\title{
Prioritising University Research: A Critique of the Kemp Reforms
}

\author{
Harry Clarke
}

$I^{1}$ n June 1999 Australia's Minister for Education Training and Youth Affairs, Dr. David Kemp, released New Knowledge, New Opportunities (hereafter, the Report) to set out the government's provisional tertiary education research and research training policy. Six months later, Knowledge and Innovation (hereafter, the Policy Statement) was released. This accounted for public discussion of the Report and provided policy conclusions. There were revisions in policy direction from the earlier Report but its core recommendations were retained. The Report remains of interest because it rationalises the Policy Statement. Both documents focus on encouraging research responsive to industry needs. The institution for achieving this is a restructured Australian Research Council (ARC) that will:

- Administer a unified National Competitive Research Grants Programme.

- Assist in linking business with research institutions.

- Provide strategic research direction advice to Government.

- Establish a broad verification framework supported by Research and Research Training Management Plans.

- Introduce performance-based funding of research training.

- Create a collaborative program to address regional needs.

While universities are given a priority-setting role for research and research training, their funding becomes dependent on past successes in gaining funding from all sources (including industry), their success in attracting students and their research output. A portable scholarship scheme forces competition for research training.

This paper critiques these policies.

\section{Assumptions and Objectives}

Recent emphasis on the importance of research in 'knowledge-based' economies suggests that certain types of public or privately financed research best enhance economic growth via a cooperative Triple Helix relation between universities, government and industry (Etzkowitz and Leydesdorff, 2000). Knowledge production is not seen as a disinterested pursuit providing free public goods. Instead discoveries are seen as delivering privately appropriable economic gains

Harry Clarke is Reader in Economics at La Trobe University. 
provided researchers are entrepreneurial and intellectual property rights support discoveries.

The Report and Policy Statement are attempting to prioritise research, to enforce property rights and to foster an entrepreneurial culture in Australian universities. These documents see knowledge creation as occurring increasingly in:

- Multidisciplinary teams rather than individual or discipline-based efforts.

- A global environment where international links provide business and research talent migration opportunities.

- An environment producing much knowledge but deficient in entrepreneurial culture.

They therefore argue that Australian universities should:

- Display 'global excellence' in fields where they are research active.

- Be centrally managed using broad ARC objectives.

- Be locally managed by more specific, market-oriented proximate objectives.

These presumptions are first discussed. Then the suggested reforms are analysed.

\section{Research is Increasingly Team-Based}

The presumption that research is increasingly 'team-based' and 'multidisciplinary' (Report:Section 1.8) implies a case for concentrating and prioritising research to exploit scope and scale economies. Is this presumption accurate? Even if it is accurate, will proposed reforms support effective team formation?

First note that, even if multidisciplinary teams are increasing in importance, this does not mean they are (or should be) a major part of university's research. The Report does not provide evidence on the relative extent of team research but there is evidence suggesting that it is mainly important in the physical sciences (Katz and Martin, 1997). In other disciplines research specialisation is dominant. Such specialisation provides benefits as well as costs. Advantages to multidisciplinary teams are offset by transactions costs of pursuing integrated efforts from different specialisations. Such costs limit the optimal extent of integration. In cases where team-based research is sought, they also suggest arguments for outsourcing in business settings rather than through integrated teams of diverse experts inside universities. If individual rather than team-based research is of primary importance there are reduced economies from prioritisation.

Indeed, even with a 'team' basis for research it is unclear that competitive grant-giving schemes optimally foster team formation. Such schemes create incentives to dress up proposals for funding in multidisciplinary garb to attract grants. Donning this attire however need not improve research outcomes. 


\section{Research Should Be Globally Prioritised}

University research is portrayed by the Report (Section 1.11) as occurring in a global environment. Exchanges of faculty, the employment of non-nationals and modern communications imply a globally integrated environment with rapid knowledge transmission. The Report seeks to encourage this by prioritising research on the basis of global standards. There are several difficulties.

Long-standing criticisms from the humanities suggest that globally prioritised universities downplay national culture (Readings, 1996). These criticisms link globalisation (often 'Americanisation') with a declining interest in local culture and suggest that, with local cultural outputs, there is a diminished case for globalism.

In addition, Australian universities face difficulties in globalising because they are restricted from recruiting faculty globally by salary differentials that make such efforts expensive. Institutions therefore must also generate talent endogenously by capitalising on specific national resources. This seems sound policy, even ignoring cost factors, because a diversity of staffing and intellectual pursuits is important in generating innovative research. Diverse views are a source of new knowledge, so institutions should draw on local talent and local research paradigms. In addition, a globalised system will be one where talent is concentrated because of the salary differentials and associated agglomeration benefits.

A further case for national orientation in research arises from specific national advantages conferred. While global efficiency in knowledge provision may be maximised by free trade in talent within a global market for ideas, it may not optimise national advantage. Indeed the Report recognises that nationally significant research is undersupplied in a global environment thus requiring some priority for national research. However, beyond a minimum of nationally important research, it argues research should be prioritised at international 'best practice' standards. This implied two-stage procedure prioritises first at national and then at global levels. Questions over the reasonableness of such priorities then hinge on the weighting assigned at the first stage. Difficulties remain both in defining the globally prioritised component and in separating things in this way.

Note also that, with global research collaboration, the case for local research prioritisation diminishes given the reduced pressures to realise scope and scale economies particularly for individual rather than team-based research. Having an independent local focus provides incentives for diversity in forming such collaborations as well as prioritisation. While the Report considers this need for diversity, the thrust of its schemes acts to concentrate research efforts.

Once it is agreed that research should be both prioritised and diverse, the complexity of the research management task becomes clear. It need not, for example, be particularly advantageous to bring in international experts to assist the $\mathrm{ARC}$ in global prioritisations as the Report advocates. 


\section{Innovation and Entrepreneurship in Australia Are Deficient}

Compared to other OECD countries Australia spends an average proportion of its GDP on R\&D. However, the public sector, rather than business, funds most university research - in 1996 public funding provided 88 per cent of university research. The Report draws strong inferences from this. Australian research is seen as disconnected from innovations leading to economic gains and as lacking entrepreneurship to commercialise research. While evidence is not provided on these claims, various policies (tax, intellectual property, improving business awareness of research, fostering entrepreneurship in universities) are advocated to facilitate innovation.

The evidence on Australian entrepreneurship and innovation, however, is not as clear as the Report implies. From 1980-1994 Australia's high-technology exports grew at one of the highest rates in the OECD (Department of Industry, Science and Resources, 1999:Table A5). While this occurred from a low base, the growth suggests increasing innovation. Indeed, the two main OECD proxies for the value of the output created by research are inventiveness coefficients (patent applications per 10,000 population) and coverage ratios (technology exports divided by imports). Australia's inventiveness coefficient was 4.6 in 1996 compared to a total figure for the OECD of 5.8 - fifth out of 29 OECD countries. Australia outperformed Canada, the US and the UK in every year from 1990-1996 in per capita inventiveness. At 0.62 in 1996, Australian coverage ratios appear less favourable - tenth among 15 OECD countries examined. However, over 1990-96 the coverage ratio increased 72 per cent (Department of Industry, Science and Resources, 1999:chapter 5), suggesting improved innovatory performance. Clearly some foreign technology dependence makes sense for Australia that should be less self-reliant than larger countries such as Japan or the US.

A subsequent report (Department of Industry, Science and Resources, 2000) confirms that Australia has an entrepreneurial culture with high 'early technology' take-up, growth in real value-added of knowledge-based industries, tertiary education enrolments, flows of graduates into science and engineering, and high scientific publication rates. Rather than providing evidence of a weak scientific base, the Department of Industry, Science and Resources suggest the key issue is low public funding of education per capita. The Australian figure for 1995 (US\$980) was 25 per cent below Canada's figure and more than 40 per cent below those for Japan and the US.

There are conceptual difficulties in using the innovation measures here to calibrate innovation trends and entrepreneurship. But the evidence does not confirm a general failure to invent, innovate and export information-intensive outputs during the 1990s. Nor does evidence confirm a weakness in the national scientific base or in the proclivity of the private sector to innovate. 


\section{Research Quality is Declining}

The Report (Section 1.41) claims that Australian researchers are currently rewarded for the breadth rather than quality of their research and that this has reduced quality. Thus universities should prioritise research. The evidence used to suggest declining excellence is 'citation index' trends. Even if this does suggest declining standards, recent education Australian policies have had negative effects on research in ways unlinked to the processes of research funding. For example critics contend that 'creeping managerialism' during the 1990s, with the creation of a pool of research-inactive professors has had disincentive effects on research and academic standards (Clarke, 1998; Crowley, 1998). In addition, universities have been subjected to two decades of funding cuts with declining faculty salaries.

With respect to research training, the Report identifies employer dissatisfaction with narrow curricula, student complaints of poor supervision and 'wastage' due to high dropout rates. There is therefore, it claims, a need 'to broaden the base of the research training experience, strengthen the creativity, communication and problem-solving skills of graduates, and provide training opportunities and experience outside the academic environment' (Report:10).

These claims are questionable. Undergraduate curricula have been expanded and operated at lower academic levels during the 1990s to accommodate expanded entry quotas not matched by proportionate funding expansion. With the preference for classes of several hundred students, it is not surprising that basic writing and reporting skills have declined, given unfunded costs of monitoring and evaluating such work. In addition, universities have established resource-intensive programs (for example, in tourism and 'business') in areas where they have had little past expertise. These trends affect training quality irrespective of how that training is managed. Much postgraduate supervision work now involves correcting basic language and math problems - issues that industry employers of graduate students also complain of. This again partly reflects university-funding problems. Furthermore, this deteriorating funding situation is unlikely to improve in the short-term. It will fall from 3.1 per cent of total Commonwealth spending in $1994 / 95$ to 2.2 per cent in 2001/02. Public spending has already fallen from 1.5 per cent of GDP in $1975 / 76$ to 1.0 per cent in 2000 with the staff-student ratio rising from 14.4 in 1989 to 18.5 in 1998 (Karmel, 2000). Despite this tightness in funding, enrolments increased from 441,000 in 1989 to 686,000 in 1999.

Dropout rates partly reflect the screening function of training. If students abandon a program for which they are ill suited this need not imply wastage. High dropout rates may (at most) indicate a case for improved up-front information and screening. Employer preferences for 'experience' in non-academic settings partly reflect incentives within firms favouring university provision of costly, jobspecific training. 'Broadening the base' of research training can mean reducing program quality by provision of more generic skills. 


\section{Centralised Funding Will Improve Research Quality}

Current research funding arrangements are described by the Report as 'fragmented'. A connotation of inefficiency is attached to the word fragmented the implicit argument is that 'de-fragmenting' or centralising research management will offset this inefficiency. It is unclear, however, that such management, implemented as a competitive arrangement, will improve research.

Politicians and education bureaucrats have incentives to seek research outcomes that advance both their own interest group advantages and society's welfare. Two contrasting research management strategies can be contrasted:

- A top-down approach achieves central management using a competitive 'tournament' based on peer review. Universities then have nominal autonomy to choose direction, but to achieve funding, choices must reflect central priorities. The use of block grants that depend on past funding achievements likewise force targeting of central priorities. To work efficiently, central priorities must reflect social needs and must have the ability to select quality research.

- A bottom-up approach assigns autonomy to universities. The government decides how much it will allocate to research across universities and leaves it to universities to devise research programs. Then, for social efficiency, it is university priorities that must reflect social needs and academics who must be able to select quality research.

Present and proposed prioritisations contain elements of both top-down and bottom-up strategies. Present arrangements emphasise bottom-up strategies while those proposed stress top-down. An advantage of bottom-up is that prioritisations are decentralised with many independent groups assessing the social interest. Central political interests are less intrusive. In addition, efficiencies arise from the ability to utilise local knowledge and to use various policy instruments (staff recruitment, promotion, financial) to pursue quality. Possible disadvantages of bottom-up include disciplinary biases within universities and research duplication.

Some of the specific benefits claimed in the Report to arise with a top-down competitive structure seem unjustified. It is stated (again without evidence) that present arrangements encourage 'grant-getting' rather than 'long-term strategic research' (Report:10). However, 'short-termism' may increase with centralised competitive schemes if grants reflect commercial priorities and ex post reviews of achievement occur frequently (Geuna, 1999). Indeed it can be questioned how proposed reforms offset such incentives. Short-term 'grant-getting' is currently fostered by the threats and promises of research managers in universities: financial incentives are now offered to faculty who even apply for grants to offset high transaction costs of application given low expected returns. This propensity to provide incentives that drive 'grant-getting' will increase given plans to make even more funding dependent on past grants obtained. 
It is not necessary to comment further on the net advantages of the alternative schemes here. The point emphasised is that information and incentive problems mean that research effectiveness is not obviously enhanced by leaning towards central management.

\section{Proximate Objectives}

The language of Report proposals is clichéd ('leading edge', 'self reliant', 'dynamic', 'excellence', 'entrepreneurial') but its core stated proximate objectives for tertiary institutions seem plausible at first sight. The Report seeks:

- Excellent research of world standard with a long-term orientation.

- Tertiary autonomy to determine what is researched and how (with a view to being responsive to global markets).

- Institutional responsiveness to informed student needs.

- Transparency, contestability and accountability in use of research funds.

One might seek to qualify the desirability of an unrestricted pursuit of excellence. There are educative payoffs from various levels of research and much research in Australian universities would cease if requirements for global excellence were imposed. Moreover it is unclear what is meant by excellence. Australian vice-chancellors regularly proclaim a commitment to excellence and describe programs as 'world standard' as a feeble marketing device. (Feeble because it is so universally and uncritically applied. At best there is defensive value in describing programs as excellent because other programs do so). Describing programs as excellent relative to others however promotes intellectual arrogance and a loss in cooperation between institutions (Brett, 2000). Words such as 'excellent' provide a language enabling weak comparisons of programs but such comparisons have low value given their lack of a clear referent: at best they weakly integrate divergent concerns (Readings, 1996:22-23) — who in a disputatious faculty will disagree with pursuing excellence?

While autonomy is an ultimate, as well as proximate objective, this is not pursued in proposed policies. Universities choose what to research given an ARC agenda that determines funding.

Encouraging institutional responsiveness to student needs seems laudable but asymmetric information issues in relations between suppliers and users of research training services make this an inappropriate ultimate objective (Clarke, 2000). Students do not initially understand what they need to know. Therefore relying on their revealed demands may provide inferior outcomes to rigorously preselecting academic faculty and then relying on academic judgement to mentor students into quality research.

Finally, use of competitive tournaments to obtain transparency in funding can result in higher transaction costs of research than would non-competitive ex post funding to those who deliver quality research outcomes. Issues of transparency and accountability in gaining research funds become crucial with a top-down 
centralised research prioritisation. In a decentralised system, local knowledge makes it easier to assess comparative research productivity.

Neither the Report nor Policy Statement provides argument supporting the premises underlying their arguments for prioritisation. Claims regarding the team character of research, a claimed lack of Australian entrepreneurial zeal, alleged short-termism in current research grant applications and claimed poor performance of research training are not backed up.

\section{The National Competitive Grants Tournament}

The Report sees prioritisation of research as best facilitated when universities make individual judgements of their own strengths. Despite this the Government would still use funding incentives based on ARC strategic advice to encourage 'sensible' prioritisations. As the Policy Statement notes, '... the new ARC Act will provide the Minister with the power to give guidance to the ARC on the broad direction of its research activities within the context of the strategic planning process, including the ... allocation of grants.' (Chapter 6:5).

Given an institution's research priorities and its consequent academic direction, projects will be advanced for funding through investigator-initiated proposals. The case for funding will then be assessed via a single ARC program subsuming all existing programs (except the Small Grants Scheme funded under the Institutional Grant Scheme). This is the National Competitive Grants Programme (NCGP). Current ARC review procedures will be 'improved' by giving a voice to industry. The reformed ARC will engage visiting researchers with experience in research management, to respond to emerging disciplinary and cross-disciplinary developments and to the needs of emerging researchers. Review committees will include discipline-specific international experts to rank projects.

The NCGP consists of a 'discovery' element to encourage excellent individual or team proposals and a 'linkage' element to promote collaboration between institutions, industry partners and groups such as the CSIRO. Both elements are assessed using peer review, which includes potential users to assess likely economic benefits 'as well as social and cultural development.'(Report:38). The balance between forms of funding has been much discussed. In the Policy Statement, the discovery component is described as covering 'fundamental' research, but this is seen as implemented 'within a wider framework that encourages links with users of that research' (Chapter 6:3). Further, 'It is a legitimate expectation that public investment in research will pay social dividends through contributions to problem solving as well as providing commercial opportunities' (Chapter 6:5). Blurring distinctions between applied and basic research makes it difficult to assess how much basic research will remain supported and only weak guarantees are provided: '.. the current balance between basic and applied research would be maintained for the time being' (Chapter 6:6). 
A feature of NCGP is that all Australian academic institutions are brought under its umbrella. For example in the Report, it was questioned whether the Australian National University's Institute of Advanced Studies - currently blockfunded - should be brought under the NCGP. The Policy Statement subsequently announced that Institute funding will become contestable, heralding the end of block funding. While criticisms should be made of the performance of the ANU Institutes, the proposition that all research should come under the competitive umbrella is questionable if only because implications of this new prioritisation are so uncertain.

Government will have a role in mapping out 'broad' strategic guidelines for research spending favouring areas such as biotechnology. The word 'broad' here is presumably inserted here to avoid impressions the Government is 'picking winners' though this is the effect. Government would also intervene to ensure universities provide environments conducive to excellence, to applying research in the 'national interest' and to structuring incentives to encourage 'enterprise and innovation'. These objectives are ambiguous and potentially permit restriction of university autonomy and the promotion of questionable research options. Would the Government favour the Multi-Function Polis, renewable energy or very fast train projects? These dubious proposals have all received political support on 'national interest' grounds.

The NCGP allocates funds via a tournament. The Government declares its broad strategic research guidelines and the ARC then prioritises on this basis with weight given to industry concerns. Individual universities then 'autonomously' determine the direction given to this prioritisation. Individuals and teams submit proposals for funding and projects chosen are those ranked highest by tournament peer and industry panels. There are difficulties here.

\section{NCGS Science Model Bias}

The ARC procedure is an 'experimental science-based' view of how research proceeds. Research is viewed as an 'open loop' process with fully specified objectives implemented as a pre-planned procedure. Research is the implementation of this procedure with an interpretation of resulting outcomes.

Research however seldom proceeds this way in social sciences and, indeed, in many natural sciences. Moreover, insisting on such methodology can bias rewards toward easy-to-justify, though contrived, proposals rather than quality cerebral research.

Academics, outside the experimental sciences, implement research not by employing research assistants using purchased equipment and then conducting experiments but by reading, calculating and thinking. The process is 'closed loop' rather than open loop with objectives and strategies for achieving objectives changing as perceptions evolve. ${ }^{1}$ Closed loop research is implemented by

1 The terms closed loop and open loop come from control engineering. Open loop plans have all procedural information known initially. Closed loop plans allow for procedural revisions as information unfolds. 
individuals perhaps in dialogue with colleagues. The main input is time. While, under current large ARC Grant schemes, individuals can buy time 'out of teaching' for such research, this seldom occurs because of difficulties in discriminating between competing claims for teaching relief and because cerebral research has a closed-loop, difficult-to-sell character. What has therefore occurred is a substitution of resource-using projects for reflective research. Deans and Vice-Chancellors place weight on sponsored research, creating incentives to substitute resource-using projects for those relying on thinking. This creates the concern in preparing research proposals of finding items to budget - some departments are now overloaded with computers, unread books and journals as well as idle research assistants as academics scramble to devise ways of spending resources creatively accessed from the ARC. Past ARC Grant procedures in Australia have induced waste through the diversion of intellectual activity into inefficient resource-using activities. Expanding such programs increases this waste.

\section{NCGS Industry Orientation}

The Report and Policy Statement have an overwhelming message, repeated page after page, that more industry-relevant $R \& D$ is what is required. The Report sees university/industry collaboration creating positive externalities. Academics gain commercial focus while industry accesses a broader knowledge base. However, external benefits must work in both directions for such a contract to be necessary. If the only external benefits accrue to firms then employment contracts awarded to university researchers, internalise firm benefits. For example, with respect to teaching, firms can extend their training departments into 'universities'. Indeed over 1,000 US corporations now have their own universities with the goal of achieving tighter control and ownership over learning by linking learning to business goals (Meyer, 1998:ix). The same idea can be extended to corporate research. This is the efficient market solution unless there are spin-offs from such research to universities.

Without externalities between industry and universities there are arguments against funding industry-relevant $R \& D$ in universities. The notion that this research can be provided at low-cost in publicly funded (and therefore low-cost) universities ignores the opportunity cost of funds used. Moreover, a case for dedicated provision holds even with general spill-overs to society from research: even when there are public good attributes, subsidies are most efficiently directed to the specific research in firms (or universities) rather than by fostering joint efforts. When research is a pure public good universities should publicly provide it.

Empirical evidence supports the view that basic research within firms is a more important determinant of productivity growth than R\&D. In addition the most effective R\&D research in firms is privately funded (Adams and Jaffe, 1996). Since most basic research in industrial societies occurs in universities, it is 
risky to redirect such work by emphasising industry-orientation in publicly funded university research.

\section{NCGS and Research Concentration Among Universities}

Economies of scope and scale exist in research when it is capital intensive (as in physical sciences), multi-disciplinary and when there are high transaction costs of preparing funding proposals. The presence of fixed costs (minimum library requirements, laboratory or equipment needs) create arguments both for prioritisation among universities into dedicated research or teaching institutions, and of research tasks within universities - these priorities reflecting minimum investments needed to generate useful information. University departments with extensive research budgets, large administrative staff and low teaching loads have advantages in achieving funding of such research.

Individual-based, curiosity-driven research that forms the bulk of research in social sciences is much less subject to scale economies, particularly given modern media for transmitting messages and desktop computers for computing and organising data.

Applying a competitive research funding mechanism will further concentrate research into established institutions that currently implement most research. Other institutions will gain proportionately less funding and will drift towards their earlier focus of vocational teaching. Thus, plans to make research funding contestable will undo university reforms of the late 1980s, which sought to expand the range of institutions doing research. Market forces were eroding the effects of these reforms anyway - the new institutions have been under funded and achieving neither vocational nor non-vocational needs (Clarke, 2000).

The benefits of such a strategy are the costs saved through non-replication of research and the exploitation of economies in multidisciplinary, team-based research efforts. Costs comprise the losses of non-science based research particularly from investigators outside the larger wealthy universities. This is additional to costs from distorting practices within established universities through adverse effects on those not utilising science-based research paradigms.

\section{NCGS and Non-Vocational Research}

The Report and Policy Statement emphasise that non-vocational research effort and cultural pursuits will be protected. Often this is done briefly and in passing, seemingly as an afterthought to protect authors from charges of philistinism. Given that markets do not exist to value non-vocationally directed research, details of how non-industry related research is to be prioritised are necessarily vague in a document emphasising economic arguments for prioritisation. The suspicion, given emphasis on industry needs, is that underprovision will occur.

A criticism of these documents (and the earlier West Report) is their narrow perspective given education's diverse aims. Vocational objectives tied to immediate social needs are one goal. Other aims include the cultural needs of 
those educated, public good needs and ideas of changing attitudes to create a better society. The Report's emphasis on industrial output is consistent with a view that mainly sees private goods as contributing to social prosperity. As mentioned, alternative views of a university see its role in contributing to national culture as well as economic growth. Universities assemble knowledge that helps to develop individual critical powers and character. Knowledge acquisition becomes a 'conversation' defining an individual's identity, their social role and values. Such a liberal approach is productively efficient and culturally enriching, if markets undersupply cultural outputs.

\section{Flaws in the NCGS Ranking Procedure}

Imperfections exist in the proposed ranking procedure for several reasons.

First, the NCGS denies any developmental role for research funding. The NCGS response to poor research performance (measured by grants gained) is to trim funding. An alternative approach would be to inject funds to improve performance giving funding a developmental role.

Second, NCGS tournaments award big prizes to those who win - but nothing to losers. Large gains to winners offset costly possibilities of losing. Large prizes ensure participation in the process but resulting grants need not reflect research needs. A major criticism of existing large ARC Grants is that while they fund a few projects with huge grants, the more modest needs of cerebral individual research are unaddressed. This suggests static efficiency losses from the allocation of resources to projects with low marginal value and dynamic losses from the incentives created to pursue excessively large projects.

Finally, self-reinforcement phenomena result in successful individuals gaining research resources that increase future chances of research success. Unsuccessful individuals get nothing. But research success may reflect luck not talent. Thus unwarranted self-reinforcement phenomena or Matthew effects arise ${ }^{2}$. Moreover, the successful concentrate in a few large schools (whose staff selection targets grant-gaining success) where the self-reinforcement cycle is compounded by colleagues comprising the selection committees who award prizes. Funds are then further misallocated across individuals and institutions.

\section{Transaction Costs of NCGS Tournament-Funded Research}

Efficiency in research effort is not always enhanced by market provision because market-based provision of resources for research faces transaction costs. These costs offset desired incentives. Competitive tournaments provide individuals with research opportunities provided they document for review panels what they will

2 Merton (1968) calls these Matthew effects after the biblical passage 'For unto everyone that hath shall be given, and he shall have abundance; but from him that hath not shall be taken away even that he hath' (Matthew 13:12). 
investigate and how they will proceed. The costs of preparing this information are significant and intensified if, as is widely understood, investigators see proposals as a deceit designed to elicit a one-line budget. These are opportunity costs of eliciting quality research if researchers would have implemented it because they have been appropriately preselected, have intrinsic interest in research, pursue promotion or seek peer respect.

Under these conditions a better approach is the offer and conditional renew policy (OCRP). An OCRP rewards researchers if they sustain research output after being initially given start-up grants on 'trust' (here any selection criterion not involving past performance). Providing modest funding on a renewable basis conditional on achievement may outperform a research tournament since transaction costs are avoided. Moreover, the need for ex ante fantasies and exaggeration is avoided with an ex post OCRP. Agents do not have incentives to deceive funding agencies by formulating proposals designed to impress rather than to work.

The NCGP involves evaluating proposed research ex ante. A proposal's strength is compared to others with only an applicant's Curriculum Vitae being used to assess whether the proposal draws on skills possessed by applicants. There are three difficulties: (i) a NCGP rewards good proposals rather than good research; (ii) a NCGP involves ex ante judgements by centralised groups subject to political manipulation; and, (iii) a NCGP can generate 'Matthew effects'. An OCRP however initially assigns research funds on a limited basis to new researchers as 'starter grants'. The funds can be used for quality research of any type. The OCRP is then renewed annually provided 'reasonable' effort, related to grant expenditure, is recorded ex post. If less-than-adequate research output is recorded then the grant is trimmed in a dampened way. If more than adequate research output is recorded the grant increases proportionately subject to budget. 'Forgiveness options' are available to researchers who fail to perform and lose funding but who subsequently perform. With OCRP transaction costs of application are minimised and there are limited incentives to cheat the grant-giver. Rewards are based on performance not promises. There is no attempt to constrain the initial research choice set but quality is rewarded. Poor research outcomes due to discovery process uncertainty are not penalised excessively while good performance is rewarded subject to budget. As an ex post scheme, the OCRP avoids difficulty (i) of the NCGP. As a scheme managed within universities OCRP avoids (ii). Finally, Matthew effects are reduced because grant trimming is dampened.

\section{Institutional Grant Scheme}

From 2001 an Institutional Grant Scheme (IGS) will provide block funding to universities. This includes all funding from previous Research Quantum and Small Grants Schemes. Current Research Infrastructure Block Grants (RIBG) are retained. Under Report proposals the RIBG was to be abolished with resources reallocated to Commonwealth Granting Agencies in proportion to their share of 
total competitive funding. The Policy Statement however decided to retain the RIBG. The IGS will be allocated under a formula reflecting success in gaining research income from all sources (60 per cent), higher degree completions (30 per cent) and publications (10 per cent).

The Policy Statement rejected Report proposals to abandon weight on publications but accepted the recommendation to weight equally all forms of research funding. With respect to the latter, the previous Composite Index formula formerly attributed to one dollar of national competitive funds grants twice the weight of a dollar from sources such as consulting. This decision to continue weighting research publications was wise since, while it is desirable to eliminate DETYA's reliance on faculty 'page counts' as a research index, eliminating publications entirely means funding is driven entirely by input measures of performance - grant applications measure inputs not research output.

All institutions undertaking research are eligible for IGS funding provided they submit a Research and Research Training Management Plan and satisfy the Australian Qualifications Framework. These plans are designed to improve research management skills. They set out institutional priorities, budgets, intellectual property policies, incentives for staff who support priorities and performance measures by which institutions seek to be evaluated. They are public documents forming the basis for discussions with Government. The transaction costs of preparing such documents are considerable and, if the past is a guide, they will be close to vacuous statements of the type skilled university bureaucrats design to appease unpopular DETYA procedures - at a private institution I visited I remarked to a senior executive that the IGS proposals created the possibility for accessing more public funds. The response: 'yes but then we must deal with DETYA and that is costly!'.

Note that the reappearance of block funding, independent of ARC competitive tournaments, is largely illusory. All IGS funding is tied partly to performance in tournaments. Individual curiosity-driven research must be partly met by a research tournament win by someone since IGS funding is partly competitive grant driven.

\section{Australian Postgraduate Research Student Scheme}

Research training is a major part of research investment ensuring the future provision of research. In 2000 the Report estimates $\$ 545$ million of university operating grants supported postgraduate research student teaching with a further $\$ 94$ million in scholarships, compared to \$345 million for targeted research.

Postgraduate training is seen by the Report as inadequate in terms of breadth and supervision quality. It claims employers see graduates as 'too narrow, too specialised and too theoretical' (Report:31). Degree attrition rates are seen as 'high' and completion times as excessive. Finally, the labour market valuation of degrees is seen as too low. Research training should therefore: (i) be broadened to account for vocational destinations; (ii) be more multidisciplinary; (iii) have more coursework; and (iv) involve interactions with industry and consultants. 
These claims are questionable. If research is seen as narrow and theoretical does this mean training should promote more vocational attributes or does it reflect industry attempts to cost save in on-the-job training? Are attrition rates high given the screening function of higher education? Does delayed completion partly reflect reliance of postgraduate students on part-time work and extensive reliance of established universities on $\mathrm{PhD}$ students to maintain teaching programs given budget cuts? Finally, if research is to be multidisciplinary and involve coursework and industry-experience, does this mean research must be pitched at a low academic level? Evidence and argument must be introduced to resolve these issues - Report claims do not become facts merely because they are stated dogmatically.

The Report argues that institutions should face incentives to improve training by placing greater weight on student preferences. Prospective students should be provided with information to facilitate an informed choice of training institution given current postgraduate student and employer views. The competitive mechanism for achieving student-orientation is via 'portable tuition scholarships' available to institutions whose research awards include external assessment (as under West proposals). Although awarded to institutions, after one year awardees could transfer to local or overseas institutions suiting their tastes. Universities that lose students would lose funding.

It is desirable for students to be given good information about research opportunities. However, as mentioned, complete student sovereignty is not sensible given information asymmetries between instructor and student. Moreover, making scholarships portable has disadvantageous effects on effort supplied by research supervisors in smaller, less well-known universities. For the reasons private firms under-invest in non-firm-specific human capital, supervisors may under-invest in training if they believe talented students will 'credential-hop' to more prestigious universities.

Scholarships will be awarded to institutions by means of a formula reflecting scholarships in the previous year, the share of total research-related income from all sources and the share of all research degree completions. Again, funding is linked to university performance in research tournaments - the twist is the emphasis on completions.

\section{The Australian Research Council}

The prospect of a unified, politically driven 'enhanced' ARC, managing most Australian university research is daunting. The judgements that have been made by politicians and DETYA bureaucrats post-Dawkins are seen by many as having degraded the Australian universities. Yet a major part of Report proposals call for a strengthening of the ARC by enhancing its role in providing advice to government and through its attempts to research manage universities by linking their research efforts to the ARC perception of national innovation needs.

Throughout history the state has sought to steer learning toward state-sought goals. Lysenko's genetics, during the time of Stalin, claimed that wheat plants in 
the correct environment produced seeds of rye. It is overly dramatic to suppose such absurdities could arise in Australia but it is conceivable that research policy will become politicised. Australian politicians have a record of supporting dubious research that reflects the narrow perspectives of interest groups. Moreover, the enhanced ARC is accountable only to Government through the Minister. The ARC will have the power to force a research agenda on any university seeking funding and has stated it will use its powers to ensure that research is in the national interest. In offering strategic advice to Government the 'Council will have regard to guidance provided by the Minister on the Government's overall economic, social and cultural objectives' (Report:46).

This raises crucial issues. Will research critical of government or of prevailing public institutions find favour in an ARC responsible to Government? Will idiosyncratic, 'curiosity-driven' research find support? While visiting or part-time academics on ARC review panels can make constrained choices under the reforms, a 'corporate board' styled ARC will determine the research mix and this board is politically driven.

\section{Conclusions and Final Remarks}

It is important to critique public reports using standards of rigour applied to research itself. Such reports directly influence public policy so costs of error are potentially higher than research subjected to peer review before being considered as a basis for policy. On this basis the Report and Policy Statement must be judged unsatisfactory.

The premises used to rationalise suggested prioritisations of university research are unjustified. No evidence is provided showing that research needs have shifted in a direction favouring team-based research. Arguments that Australia is undersupplying entrepreneurship and innovation are unsupported. Claims of declining academic standards, while perhaps justifiable, partly reflect recent Government reforms in universities and the rise of a managerial, nonacademic ethos. The view that research training procedures are failing, that 'drop out' rates are excessive and that more coursework should be introduced, are topics for analysis within universities, rather than assumptions on which a reform program should be based. Evidence of short-termism in research applications has not been provided and, importantly, arguments that short-termism will be reduced by a NCGP, seem fatuous.

That these premises are subject to dispute weakens the reform package. For example, if desired research is not team-based, the suggested case for prioritisation weakens.

Even ignoring criticisms of premises, the case supporting the advocated policies is weak. A significant difficulty is the proposal to base research funding on the outcomes of a tournament. The model used to justify this claim is sciencebased and relies on dubious claims about the need for industry orientation. The proposal would downgrade the role of individual-based and non-vocational 
research. Benefits from sought incentive effects may be dominated by transaction costs borne by applicants.

Proposals for reforming research training are flawed. Information asymmetries between instructor and student provide sound reasons for the former providing leadership on issues of academic choice. Portable scholarships will lead to incentive problems for those providing research guidance in non-major universities.

Finally, the new role of the ARC is of concern. It is simplistic to suppose research orientation in universities can be dealt with by central management. To offer universities autonomy subject to a choice set formulated by a politically driven ARC is not to offer genuine autonomy at all. The presumption is that while individual universities cannot be relied on to provide sensible research directions that a centralised determination, subject to inevitable political pressure can do this on the basis of national interest concerns. This ignores reasons for establishing distinct tertiary institutions and standard arguments for decentralising decisionmaking.

\section{References}

Adams, J. and A. Jaffe (1996), 'Bounding the Effects of R\&D: An Investigation Using Matched Establishment-Firm Data', National Bureau of Economic Research, Cambridge, Mass (NBER Working Paper No. 5544).

Brett, J. (2000), 'Competition and Collegiality', pp. 144-155 in T. Coady (ed) Why Universities Matter, Allen and Unwin, St Leonards.

Clarke, H. (2000), 'Asymmetric Information, Public Goods and Central Control: A Critique of the West Review's Education Policy', Australian Journal of Education, 44(1):76-90.

Clarke, H. (1998), 'Dumbing-Down in Australian Universities', Quadrant, September:5559 .

Crowley, F. (1998), Degrees Galore: Australia's Academic Teller Machines, Privately Printed, Wild \& Wooley.

Department of Education, Training and Youth Affairs (1999), Knowledge and Innovation: A Policy Statement on Research and Research Training, Canberra.

Department of Education, Training and Youth Affairs (1999), New Knowledge, New Opportunities: A Discussion Paper on Higher Education Research and Research Training, Canberra.

Department of Industry, Science and Resources, (2000), Knowledge-Based Activities: Selected Indicators, Knowledge-Based Economy Branch, Canberra.

Department of Industry, Science and Resources, (1999), Measuring the Knowledge-Based Economy: How Does Australia Compare?, Industry Analysis Branch, Canberra. 
Geuna, A. (1999), The Economics of Knowledge Production, Edward Elgar, Cheltenham.

Etzkowitz, H. and L. Leydesdorff (2000), 'The Dynamics of Innovation: From National Systems and 'Mode 2' to a Triple Helix of University-Industry-Government Relations', Research Policy, 29:109-123.

Karmel, P. (2000), 'Funding Universities', pp. 159-185 in T. Coady (ed) Why Universities Matter, Allen \& Unwin, St Leonards.

Meister, J. (1998), Corporate Universities, McGraw Hill, New York.

Merton, R. (1968), 'The Matthew Effect in Science', Science, 159:253-74.

Readings, B. (1996), The University in Ruins, Harvard University Press, Cambridge.

Review of Higher Education Funding and Policy, (1998), Learning for Life: A Review of Education Financing and Policy, Final Report, AGPS, Canberra.

Useful responses to earlier versions of this paper were received from referees, seminars at Monash and Melbourne Universities and the year 2000 Industry Economics Conference at AGSM. I particularly thank an anonymous referee for useful, detailed comments. 